\title{
A POTÊNCIA PARA A SIMULAÇÃO: DELEUZE, NIETZSCHE E OS DESAFIOS FIGURATIVOS AO SE REPENSAR OS MODELOS DA FILOSOFIA CONCRETA
}

\author{
Norman MadarasZ
}

\begin{abstract}
RESUMO: A filosofia deleuziana é mais conhecida como uma criação contínua de dispositivos maquinais, cujo objetivo é transformar o esqueleto figurativo no qual as formas e os modelos aplicativos vêm se sedimentar. A metáfora geológica não é, por isso mesmo, meramente aleatória. Ela tem a ver com um encontro real entre as possibilidades de movimentos criadores de dobras e as dobras mesmas como relevos formais. Pode-se supor que a primeira dessas formas geradoras, na filosofia de Deleuze, seja o simulacro. No quadro deste artigo, pretendemos retomar a análise do simulacro nos dois textos fundamentais de Deleuze sobre Platão e sobre Lucrécio.
\end{abstract}

Palavras-chave: Dispositivos maquinais. Dobra. Simulacro.

\section{THE POWER FOR SIMULATION: \\ Deleuze, NieTzSCHE AND THE Figurative CHALLENGES OF RETHINKING THE MODELS OF CONCRETE PHILOSOPHY}

ABSTRACT: The philosophy of Deleuze is best known as a continuous creation of machinic apparatuses aimed at transforming the figurative conception in which applicative forms and models sediment. The geological metaphor is thus not merely arbitrary. It is tied to a real encounter between the possibilities of creative movements of folds and the very folds considered as formal reliefs. One can thus reasonably suppose that, in the philosophy of Deleuze, simulacrum is the first of these generating forms. In this article, we will try to follow how Deleuze analyzes simulacrum in his two fundamental essays about Plato and Lucretius.

Key words: Machinic apparatuses. Fold. Simulacrum.

Doutor em filosofia pela Universidad Paris 8 e professor da Universidade Gama Filho (UGF).

E-mail: normanmadarasz@yahoo.ca

Educ. Soc., Campinas, vol. 26, n. 93, p. 1209-1216, Set./Dez. 2005 
A potência para a simulação: Deleuze, Nietzsche e os desafios figurativos...

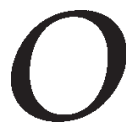

termo "simulacro" adquiriu, nos anos de 1970 e 1980, nos círculos norte-americanos da arte e da literatura, uma conotação que se tornou bastante generalizada. No entendimento ligado a esse meio, o termo tem sido muitas vezes associado ao artificial, ou seja, a um conjunto de ficçóes cujo valor é equiparável ao de uma verdade, ainda que os meios expressivos pelos quais é recebido sejam o que indica antes de tudo o seu valor. Essa recepção tardia de um conceito por tanto tempo associado ao falso, e assim ao indesejável, é uma conquista da racionalidade do ceticismo. O primeiro filósofo a desenvolver de forma mais abrangente a noção de simulacro foi Gilles Deleuze. Mais ainda, Deleuze foi quem pensou a ligação imanente do simulacro a processos igualitários como movimento natural. Longe da crença de que os movimentos igualitários são um produto utópico do passado, o ceticismo filosófico procura refinar seu entendimento desses processos como pertencentes a um contínuo natural em face do qual a cultura tem sido comprovadamente muitas vezes fraca, confusa e denegatória.

O simulacro foi apresentado por Deleuze sob um aspecto crítico e liberador. Neste ensaio pretendo rever as condiçóes pelas quais o simulacro surge como uma noção-chave na primeira filosofia de Deleuze. Argumento que o simulacro antecipa os principais gestos no sentido de uma filosofia da imanência, da multiplicidade e da intensidade. Essas noções se transformam em conceitos implicados nos paradigmas epistemológicos, e estes são cada vez mais refinados na trajetória da sua filosofia. Esta é uma outra razão para abordar o simulacro: trata-se de um protótipo de uma série de modelos filosóficos inovadores que são o motor crítico e criativo que sustenta o pensamento de Deleuze, modelos tais como agenciamento, rizoma e dobra.

Assim, a noção de simulacro encontra-se num ponto-chave da evolução do pensamento deleuziano. Desde suas primeiras publicações nos anos de 1960, Gilles Deleuze tornou-se um dos maiores comentadores da história da filosofia. Uma de suas contribuições mais importantes foi a de promover a integração de Nietzsche ao cenário filosófico francês. E, ao mesmo tempo que seu influente livro, Nietzsche e a filosofia, Deleuze iniciou em 1961 a publicação de uma série de artigos sobre o simulacro. ${ }^{1}$ Artigos estes que assinalam uma mudança de tom e de teor da sua filosofia. Eles são motivados pelo interesse em redesenhar a recepção do pensamento grego e a forma como até então se apresentava na França. Representam também uma tentativa de incentivar a filosofia no contexto 
do crescimento urbano feroz do período que se segue à Segunda Guerra Mundial. E abriram caminhos criativos que iriam tornar o trabalho de Deleuze um dos mais expressivos da invenção filosófica francesa. De fato, seu pensamento é uma afirmação da filosofia como ela se "elabora, mas nas cidades e nas ruas, inclusive no que há de mais factício nelas" (Deleuze, 1998, p. 271).

Apesar de ter-se tornado de ampla aplicação na teoria da arte, a noção de simulacro complica a estética como tal. A estética abandona os terrenos bem delimitados da filosofia da arte a fim de tratar com as superfícies menos exatas do sensorial e da teoria da sensação (idem, ibid., p. 265). Além disso, no prolongamento de seu trabalho sobre o simulacro, a estética deleuziana vai inserir-se numa relação entre corpo e linguagem. Nesse contexto, o simulacro refere-se a uma concepção específica da linguagem, bem ilustrada pelo solecismo. Um solecismo é a designação erudita de um erro sintáxico, de uma incorreção no uso da linguagem, e mais comumente significa um erro, uma falha, um engano. Para Deleuze, porém, um solecismo é como o corpo, "capaz de gestos que dão a entender o contrário daquilo que indicam" (idem, ibid., p. 293). Assim, o solecismo "superior" torna-se um dos ingredientes usados por Deleuze na integração do falso para reformular uma teoria na qual os meios expressivos diferentes do corpo adquirem um valor heurístico - um dos aspectos do simulacro é o de incluir o corpo do observador na sua observação. Identificando o simulacro com um certo uso da linguagem, Deleuze apresenta o que posteriormente chamará de dupla articulação, que designa o surgimento de formas consistentes e identificáveis como tais numa atualidade a partir da fonte sem limites, o caosmo, das formas heterogêneas mas potenciais, ou virtuais. É aqui que o simulacro vai revelar a sua estrutura modelar imanente, sobretudo a potência natural da criação ou, em termos deleuzianos, a simulação.

Além da reformulação do solecismo, é importante ressaltar que Deleuze acrescenta à crítica estética do simulacro uma derivação epistemológica e uma prescrição política. Ele estabeleceu os termos segundo os quais as verdades expressas na arte adquirem uma compreensão mais adequada, mais completa, quando as pensamos como ficções. Assim ele nos faz ver que, no domínio do saber e das ciências, conceber as formas e os objetos unicamente por meio do paradigma da causalidade mecânica implica uma redução do contexto, da instrumentalidade e da situação, 
A potência para a simulação: Deleuze, Nietzsche e os desafios figurativos...

quando esse paradigma não é completado por uma percepção das propriedades emergentes e auto-organizadoras próprias às formas e aos objetos de natureza mais complexa e totalizante. Uma vez que aceitamos essa idéia, podemos atestar uma decisão no projeto deleuziano que identifica a marginalização do simulacro levada a cabo por Platão em sua própria epistemologia e metafísica. Parece claro então que sustentar uma teoria da verdade cujo acesso ao conteúdo será limitado aos filósofos transformados em autoridades políticas é uma medida mal concebida, ou até mesmo ideológica.

$\mathrm{Na}$ divisão epistemológica platônica, os simulacros são o solecismo mesmo: erros, confusões, as cópias ruins da mímesis. Mas o objetivo geral da resposta deleuziana é o de "fazer subir os simulacros, afirmar seus direitos entre os ícones ou as cópias” (Deleuze, 1998, p. 267). Tornandoos o paradigma dos modelos não-lineares que lutam por espaço estético, epistemológico e filosófico na cidade - por isso, sua análise equivale a uma decisão política por parte de Deleuze. Como sempre, Deleuze não impõe um modelo por sobre um sistema filosófico preexistente, ele o extrai do que Platão já havia indicado no final do Sofista como uma positivação do simulacro (idem, 1988, p. 122-123). ${ }^{2} \mathrm{Na}$ medida em que ele assim o faz, aponta para o direito político de processos igualitários naturais como imanentes à pesquisa filosófica mais crítica possível no que concerne à metafísica e ao conhecimento.

No tríplice processo de extrair as formas, derivando seus padrões e prescrevendo-os em termos de ação, o papel do filósofo é central, como é mais claramente indicado na alegoria da caverna. No início, o filósofo está entre a massa de "prisioneiros" do sistema de crença no qual os objetos existem como reais e suficientes em si mesmos. As opiniōes, a doxa, desacreditam as significações interpretativas e descritivas desses objetos e das relaçôes entre eles, e até fabricam outras imagens para lhes dar sentido, ao invés de reconhecê-los como cópias das formas perfeitas. O filósofo toma o caminho caminhando para trás, até o ponto em que se pode ver uma chama viva atrás das formas bidimensionais que projetam suas sombras na parede da caverna, as quais os prisioneiros tomam como reais. No processo, vai distinguir entre duas fontes de luz, ou seja, a chama e uma outra luz que o levará a subir ainda mais alto até se encontrar fora da caverna quando vai descobrir a mundo verdadeiro e suas formas. Neste último momento, ao surgir de dentro da caverna, o filósofo encontra o saber já inscrito em sua alma. 
$\mathrm{O}$ que ficou praticamente esquecido nessa alegoria, mas fornece uma riqueza de entradas para outras pesquisas, é como o filósofo se dá conta de que existem projeçôes melhores e piores, cópias melhores ou piores. Em outros textos, Platão distingue hierarquicamente entre esses dois tipos de cópias, chamando de "eidola" os melhores, e de "fantasmas" ou "imagens" quando deformam ou falsificam a adequação aos modelos. O segundo tipo marca uma fidelidade empobrecida, que torna as essências irreconhecíveis, ou pode ser um caso de não-verdade. Entre as cópias ruins, Platão localiza não somente os erros, as distorções e os resultados miméticos pobres, mas também as figuras deliberadamente marginais e independentes.

$\mathrm{Na}$ crítica nem sempre explícita que Nietzsche faz de Platão, podese perceber uma multiplicação lúdica das figuras da caverna em que o filósofo vem se dissolver. Com efeito, uma vez que esses itens da caverna começam a mudar, o movimento dentro da caverna envolve o próprio pensador, a um tal ponto que ele nem sabe mais com qual imagem-tipo se confronta. Não somente deixa de haver uma abertura, mas, se se pode ainda falar de caverna, um movimento em espiral atrai o pensador ainda mais para dentro. Este é o momento do qual parte Deleuze, quando o movimento começa a girar em torno do seu próprio eixo, a complexidade da viagem determina-se por uma profundidade autodivisora, uma camada de realidade abrindo-se sobre outra, até que o viajante descobre o modelo como sendo um labirinto, e a separação das realidades encarnada num jogo de espelhos, um jogo de máscaras, entre as figuras tradicionais dos atores no labirinto.

Deleuze transforma as cavernas múltiplas nietzscheanas numa coerência de labirintos, na qual o filósofo estoicamente se utiliza de máscaras a fim de se dissolver na simulação fundamental, especialmente a fim de andar na linha de fora (ligne $d u$ dehors) cada vez mais perto da beira, como se fosse o movimento para fora do labirinto que apresentasse um risco maior que o do minotauro que reina no seu centro. Politicamente, a transformação enraíza-se numa associação do simulacro com a exclusão dos poetas da polis, tal como ela se declara no Livro IV da República. Lembremos que os poetas são aí descriminados por terem deliberadamente falsificado a imagem dos deuses como corruptos. E sobretudo por produzirem personagens pretensamente conforme a seus modelos reais sem possuírem o saber que lhes outorgam, isto é, porque produzem simulacros de generais, governantes, médicos etc. As- 
A potência para a simulação: Deleuze, Nietzsche e os desafios figurativos...

sim, os poetas com suas produções aparecem como tipos-cópias que não podem servir de modelo para os cidadãos de um Estado filosófico ideal baseado na justiça.

No sentido epistemológico, o simulacro denota o processo de criação conceitual como tal. Isso pode ser entendido de duas maneiras. Primeiro, no sentido óbvio, pelo qual o simulacro faz surgir suas regras próprias a partir da sua estrutura. Segundo, como um meio ou um processo pelo qual as verdades são mais especificamente formuladas, a criação conceitual encarnada no simulacro evoca um modelo epistemológico de subjetivação (os planos de consistência e imanência). Esse conceito implica uma crítica da mímesis na medida em que os objetos do mundo antes de serem individuais pertencem a totalidades, grupos, encarnando uma série de relações diversas. Surgem a partir do sem-forma, de uma fonte de elementos díspares, "compossíveis", agregando-se em focos vizinhos (Deleuze, 1998, p. 265), por meio de um processo de criação de semelhança, a simulação, "a potência para produzir um efeito" (idem, ibid., p. 268).

As estruturas de totalidades e de grupos compartilham uma autoconservação profunda, fornecendo as condiçōes para adquirirem estabilidade, para tornarem-se identificáveis até serem batizadas identidades. $\mathrm{O}$ processo assim entendido vincula dois conceitos nietzscheanos capitais: o eterno retorno e a vontade de potência. A simulação é a própria potência da natureza no processo contínuo de surgimento de identidades a partir de um fundo de diferença, isto é, a diferença como fonte sem relação das formas por vir. Como escreve Deleuze, o simulacro "é construído sobre uma disparidade, sobre uma diferença, ele interioriza uma dissimilitude" (1998, p. 263). O simulacro repete a simulação em sua própria estrutura numa relação ao mesmo, à semelhança e à diferença num mundo de ordem e de identidade, ou seja, um mundo de múltiplos ou de identidades que nós reconhecemos como tais. Deleuze produz assim a derivação do simulacro como um modelo epistemológico.

Consideremos agora a prescrição política com a qual Deleuze investe o modelo. Se o simulacro vem agravando problemas, é por causa da injustiça da sua marginalização. A contraproposta é a de afirmar os direitos do simulacro de estar no meio de todas as cópias e imagens (idem, ibid., p. 267). Como Deleuze escreve explicitamente, "o simulacro não é uma cópia degradada, ele encerra uma potência positiva que nega tanto 
o original como a cópia, tanto o modelo como a reprodução" (idem, ibid.). Além disso, Deleuze demonstrou como o simulacro é o protótipo do processo de subjetivação. Dessa forma a necessidade de atribuir direitos políticos ao que tem sido julgado como falso está enraizada nas extensões do simulacro quando aplicado conceitualmente. Mesmo o falso - ou o pseudos - merece ter direitos iguais: mesmo o pseudo pertence a um processo igualitário dos pretendentes à produção e à formulação de verdades. Em contrapartida, os processos igualitários vêm se inscrever nas condiçōes e regras do simulacro. Assim, nesta derivação específica, enquanto conectados ao modelo epistemológico, os processos igualitários como produção de verdade se inserem em um modelo natural.

Mais acima mencionei que sem atribuir ao simulacro uma figura composta de três painéis: estético/epistemológico/político, quando pensamos os modelos deleuzianos ulteriores, corremos o risco de esquecer sua intensidade igualitária. Porque esses modelos seguem o motivo do simulacro, complicando-o e enriquecendo-o. Tentei também mostrar como a derivação do simulacro se apóia numa idéia do direito, colocando o simulacro na chave do pensamento e da ação filosófica em nossas metrópoles modernas, sendo a modernidade definida como "a potência do simulacro" (idem, ibid., p. 270). Como derivação em termos do movimento real da natureza, podemos reconhecer o simulacro como integrando também, de modo imanente, estruturas não-lineares como se eles mesmos lutassem por espaço dentro de nossas ciências, enquanto o fluxo contínuo de processos igualitários na natureza transforma nossas filosofias.

Também ressaltei como a filosofia de Deleuze se conformando a esta estrutura tríptica nos permite avaliar se o paradigma platônico ainda está operando dentro nosso entendimento do simulacro. A dupla articulação leva ao simulacro como necessariamente afirmando o ceticismo quanto à verdade absoluta. Em contrapartida, o fato de que as verdades são relativizadas com relação às totalidades diversas e aos seus requisitos específicos não deveria excluir a extensão universal, isto é, o aspecto "natural" desse modelo.

Ressaltei o padrão tríptico do simulacro segundo Deleuze para demonstrar que a mera insistência na estética, no sentido mais amplo do termo, conduz a uma afirmação social que não precisa de Deleuze para legitimar-se, como se Deleuze oferecesse um impulso mais forte ao individualismo, à ficção e ao artifício. Como simples afirmações parciais da 
A potência para a simulação: Deleuze, Nietzsche e os desafios figurativos...

diferença, o individualismo artístico e boêmio é apenas factício, a cópia de uma cópia, aquilo mesmo que Deleuze coloca em oposição ao simulacro. $\mathrm{Na}$ verdade, nenhuma destas disposições está entre as totalidades que Deleuze descreve como fruto das formas mais notáveis de processos morfogenéticos, e nenhuma delas são instâncias de um elã natural que se manifesta através do tempo em configurações históricas diferentes dos processos igualitários. O simulacro é afirmado numa pincelada ou em se fazendo vibrar uma corda, na derivação de um teorema ou de uma regra e na prescrição de uma filosofia política que bem pode ser culturalmente reprimida, mas volta, sempre volta, nas simulaçóes da natureza.

Recebido em maio de 2005 e aprovado em julho de 2005.

\section{Notas}

1. Nietzsche e a filosofia foi publicado em 1962, ao passo que os artigos foram republicados em ordem não-cronológica no anexo da versão original de Logique du sens, publicado em 1969. Eles tratam de Lucrécio (1961), Pierre Klossowski (1965), Michel Tournier (1967) e Platão (1967), sem contar o desenvolvimento formal do conceito de "simulacro" em Diferença e repetição (publicado em 1968 na França).

2. Ali Deleuze remete especificamente ao final do Sofista, no qual Platão, procurando um modelo adequado para descrever o antagonista do filósofo, é obrigado a criar um simulacro, posto que esse modelo não se refere a uma idéia preexistente. Apesar de somente "imitar" o sábio, o sofista também descende de uma linhagem de produtores de imagens; em suma os sofistas "são especialistas do discurso e fabricantes de artifício". Cf. Platão, O sofista, $268 \mathrm{c}-268 \mathrm{~d}$.

\section{Referências bibliográficas}

DELEUZE, G. Lógica do sentido. 4. ed. Trad. de Luiz Roberto Salinas Fortes. São Paulo: Perspectiva, 1998.

DELEUZE, G. Diferença e repetiçāo. Trad. de Luiz B. L. Orlandi e Roberto Machado. Rio de Janeiro: Graal, 1988. 